\title{
Special issue on ambient advancements in intelligent computational sciences
}

\author{
Shailesh Tiwari ${ }^{\mathrm{a}, *}$, Munesh Trivedi ${ }^{\mathrm{b}}$ and Mohan L. Kohle \\ ${ }^{\mathrm{a}} A B E S$ Engineering College, India \\ ${ }^{\mathrm{b}}$ REC, Azamgarh, India \\ ${ }^{\mathrm{c}}$ University of Agder, Norway
}

The field of computational sciences always deals with the search of finding the innovative solutions of the problems by proposing different techniques, methods and tools. Generally innovation refers to find new ways of doing usual things or doing new things in different manner but due to increasingly growing technological advances with speedy pace, Smart Innovations are needed. Nowadays, there is massive need to develop new 'intelligent' 'ideas, methods, techniques, devices, tools' in the field of Computational Sciences.

Over the last few decades, advancements in computational sciences have gained to impressive level by drawing attention of researchers, academicians and technocrats. The techniques, methods and tools developed under the aegis of computational sciences not only improve very common areas of our daily life, but also areas of education, health, transportation, robotics, data sciences, data analytics, production industries, and many more. Thus, Ambient Advancements in Intelligent Computational Sciences is the need of the society of tomorrow.

Nowadays, technology is changing with a speedy pace and innovative proposals that solve the engineering problems intelligently are gaining popularity and advantages over the conventional solutions to these problems. It is very important for research community to track the ambient advancements in

\footnotetext{
*Corresponding author. Shailesh Tiwari, ABES Engineering College, India. E-mail: shail.tiwari@yahoo.com.
}

the field of computational sciences. The Special Issue on "Ambient Advancements in Intelligent Computational Sciences A2ICS-2018" focuses on latest research results and exchange views on the future research directions in the field of computational sciences. This Special Issue covers those intelligent systems, paradigms, techniques, technical reviews that employ knowledge and Intelligence in a broad spectrum. A sincere effort has been made to make it an immense source of knowledge for all and includes 50 articles in this special issue. The special issue is further categorized into three different tracks named as Intelligent Communications and Networking, Intelligent Computational Sciences, and Smart Computing Techniques.

A2ICS-2018 received around 280 submissions from around 400 authors of 17 different countries such as USA, Spain, South Korea, Norway, Malaysia, China, Italy, Iran, India, Germany, Greece and many more. Each submission has been gone through the plagiarism check. On the basis of plagiarism report, each submission was rigorously reviewed by at least two reviewers with an average of 2.8 per reviewer. Even some submissions have more than two reviews. On the basis of these reviews, 50 high quality papers were selected for publication in this special issue, with an acceptance rate of $17.8 \%$.

We would like to express our gratitude to Prof. Reza Langari, Editor-in-Chief and the members of editorial board, Journal of Intelligent \& Fuzzy Systems-Applications in Engineering and 
Technology for giving us the opportunity to edit this special issue on Ambient Advancements in Intelligent Computational Sciences. We would also like to express our special thanks to Mr. Maarten Fröhlich, IOS Press for providing his kind support and guidance, whenever and wherever required. We extend our heartfelt gratitude to the reviewers for showing their concern and efforts in the review process. We are also thankful to all the contributors who have submitted their high quality papers. We are indeed thankful to everyone directly or indirectly associated with the editing of this special issue.

We hope that this fine collection of articles will be a valuable resource for Ambient Advancements in Intelligent Computational Sciences for Journal of Intelligent \& Fuzzy Systems- Applications in
Engineering and Technology readers and will stimulate further research into the vibrant area of computational sciences.

Shailesh Tiwari ABES Engineering College, India

Munesh Trivedi

REC, Azamgarh India

Mohan L. Kohle University of Agder Norway 